\section{Comparison of the GAP Model and the Lung Allocation Score in Patients with Idiopathic Pulmonary Fibrosis/Intersti- tial Lung Disease Undergoing Lung Transplantation}

\section{Leann L Silhan*, Cheilonda Johnson, Pali D Shah and Sonye K Danoff}

Department of Medicine, Division of Pulmonary and Critical Care Medicine, Johns Hopkins University School of Medicine, Baltimore, USA

\begin{abstract}
Background

Idiopathic Pulmonary Fibrosis (IPF) and other advanced Interstitial Lung Diseases (ILD) are often fatal without Lung Transplantation (LT). Several models for predicting mortality risk have been developed including the GAP (gender, age, physiology) model. Similarly, the Lung Allocation Score (LAS) has been shown to predict the risk of mortality within the first year posttransplant. We hypothesized that a disease specific mortality model (GAP) might be superior compared to the predictive power of the LAS model for overall mortality within the first year posttransplant in patients with IPF and ILD.

\section{Methods}

A retrospective analysis of 72 patients with IPF or ILD listed for transplant between March 2005 and September 2013 at a single academic medical center was conducted. Logistic regression models were used to compare the relative contribution and explanatory power of the LAS and GAP for predicting mortality within the first year posttransplant using likelihood ratio chi-square tests $\left(\mathrm{G}^{2}\right)$ and the area under the Receiver Operator Characteristic (ROC) curve.

Results

Fifty-eight subjects received lung transplant and fourteen were removed from the waiting list. Forty-two subjects survived past the first posttransplant year of the 58 transplanted subjects, six had unavailable data. Fifty-two IPF/ILD subjects were included for
\end{abstract}

*Corresponding author: Leann L Silhan, Department of Medicine, Division of Pulmonary and Critical Care Medicine, Johns Hopkins University School of Medicine, Baltimore, USA, Tel: 410-955-4176; Fax: 410-614-1652; E-mail: Isilhan1@jhmi.edu

Citation: Silhan LL, Johnson C, Shah PD, Danoff SK (2016) Comparison of the GAP Model and the Lung Allocation Score in Patients with Idiopathic Pulmonary Fibrosis/Interstitial Lung Disease Undergoing Lung Transplantation. J Pulm Med Respir Res 2: 007.

Received: June 17, 2016; Accepted: July 29, 2016; Published: August 12 2016 analysis. Fourteen $(26.9 \%)$ of the 52 died within the first posttransplant year. GAP and LAS were poorly correlated $\left(r^{2}=0.033\right)$. Neither GAP nor LAS was predictive of early posttransplant mortality in IPF/ILD (C-statistic range 0.62-0.67).

\section{Conclusions}

Our data demonstrate poor correlation between GAP and LAS, which may be due to the GAP score being dependent on the diffusion capacity variable which is not included in the LAS. In our dataset, neither correlated well with early posttransplant mortality.

Keywords: Idiopathic pulmonary fibrosis; Interstitial lung disease; Lung allocation score; Lung transplantation; Lung transplant prognosis

\section{Introduction}

Idiopathic Pulmonary Fibrosis (IPF) is a uniformly fatal progressive fibrotic lung disease with a mean survival of 3-5 years; currently lung transplant is the only therapy that prolongs survival $[1,2]$. Other Interstitial Lung Diseases (ILDs) have a better prognosis in general, but some progress to advanced fibrotic lung disease that is fatal without Lung Transplantation (LT) [3-6]. In contrast to other solid organ transplant, lung transplantation volumes continue to grow. Over 3,600 adult lung transplant procedures were reported in 2013 according to the International Society of Heart and Lung Transplantation registry, the highest in a single year to date. ILD/IPF is a leading indication for LT, accounting for $29 \%$ of all lung transplants worldwide $[7,8]$, and is the most common diagnosis for LT (37\%) in the United States [9]. In general, short- and long-term survival post-LT have continued to improve, but the median survival remains quite low at 5.6 years for all diseases, and lower, 4.5 years, for IPF/ILD $[7,8]$. The one-year survival of all adults who underwent primary lung transplant between January 1990 and June 2013 was $80 \%$, and improved overtime to $84 \%$ in the 2009 to 2013 era. However, the one-year survival for IPF remains significantly lower at 73-76\% [7-9].

Individual ILD/IPF patients demonstrate widely variable clinical courses and survival, with some progressing rapidly to death, and others enjoying years of little or no progression [10,11]. Hence, predicting prognosis and timing of referral for LT is imperative for best patient outcome.

Historically, individual variables have been associated with mortality in IPF, but none have predicted prognosis in isolation [12-15], and other clinical prognostic models combining variables have had little impact [16-18] due to difficulty in clinical use and lack of validation. The GAP model was designed to develop a multidimensional prognostic staging system initially for IPF, then for other ILDs, by using commonly measured variables, specifically gender $(G)$, age (A), and pulmonary physiology (P) including Forced Vital Capacity (FVC) and Diffusion Limitation of Carbon monoxide (DLCO) (Table 1). These models performed well in two separate derivation and validation cohorts with c-index of approximately 70 in the GAP-IPF study and c-index of 74 in the modified GAP-ILD study in predicting mortality at 1,2 , and 3 years $[6,19]$.

In response to a flawed time-based waiting list, the Lung Allocation Subcommittee was formed by the Organ Procurement and 
Transplantation Network in 2005. With algorithms to calculate historic waiting list mortality as well as posttransplant mortality, they formed the Lung Allocation Score (LAS) (Table 1). The LAS is an adjustable scale from 0 to 100 that represents a weighted combination of each candidate's predicted survival during the following year on the waiting list and his/her predicted survival during the first year following a transplant [20]. Since the implementation of the LAS, the overall number of LTs has increased, percent mortality on the wait list has decreased, and numbers of LT for IPF/ILD has increased $[7,9]$. However, it has also been shown in IPF and other lung diseases, that recipients with the highest quartile LAS scores, have higher early posttransplant predicted mortality $[21,22]$.

\begin{tabular}{|c|c|}
\hline \multicolumn{2}{|c|}{ Variables of the GAP index and LAS } \\
\hline \multicolumn{2}{|l|}{ GAP Index } \\
\hline & Gender \\
\hline & Age \\
\hline & Physiology (\%FVC and \%DLCO) \\
\hline \multicolumn{2}{|c|}{ LAS (Lung Allocation Score) } \\
\hline & Diagnosis (IPF/ILD is diagnosis Group D) \\
\hline & Age \\
\hline & BMI \\
\hline & Diabetes \\
\hline & Functional status \\
\hline & FVC (\% predicted) \\
\hline & Pulmonary artery systolic pressure \\
\hline & Oxygen requirement at rest \\
\hline & 6 minute walk distance \\
\hline & Mechanical ventilation or extracorporeal support \\
\hline & PCO2 \\
\hline & PCO2 increase by $>15 \%$ in 6 month period \\
\hline & Serum creatinine \\
\hline
\end{tabular}

Table 1: Variables included in the GAP index and Lung Allocation Score.

\section{Abbreviations}

FVC: Forced Vital Capacity

DLCO: Diffusion Limitation of Carbon Monoxide

BMI: Body Mass Index

PCO2: Partial Pressure of Carbon Dioxide

No studies have thus far examined the relationship of the GAP index and LAS, or evaluated how the GAP index may correlate with post-LT outcomes. With the knowledge that the GAP score predicts mortality in the natural course of IPF/ILD, we investigated its role in predicting post-LT outcomes.

\section{Methods}

\section{Subjects}

We retrospectively investigated the medical records of 72 subjects with IPF or other ILD who were listed for lung transplant at the Johns Hopkins Comprehensive Transplant Center Lung Transplant Program from March 2005 to September 2013 (Figure 1). There was missing data on 10 subjects; 4 of these were removed from the wait list; 6 were transplanted, of whom 4 survived and 2 died. The missing data was due to absence of diffusion capacity (DLCO) data in 10 of 10 cases; thus GAP index could not be calculated. In these 10 cases, this is due to DLCO not being performed, which differs from the patient being unable to perform the DLCO maneuver, which is applied in the GAP index scoring [6,19]. A total of 14 of the
72 wait listed patients were removed from the LT waiting list; 10 died, 3 were removed for being deemed too well and are currently alive, and one was lost to follow-up. Of the subjects included in the analysis, the diagnosis of IPF was made pre-transplant in 41 subjects transplanted (biopsy-proven usual interstitial pneumonia in 20, inconclusive biopsy in 2, and clinical/radiographic diagnosis in 19 subjects) and confirmed based on Usual Interstitial Pneumonia (UIP) histopathology on explanation in all 41 cases. The diagnosis of other ILDs was made pre-transplant in 11 patients who were transplanted (biopsy-proven diagnosis in 8 subjects, clinical/radiographic diagnosis in 3 subjects) and confirmed on post-explant histopathology.

\section{Methods}

The GAP score was calculated as close in proximity to listing for LT as timing of pulmonary function testing allowed (median difference in LAS to GAP calculation was 5 weeks). The study was approved by the Institutional Review Board of JHU (IRB No. NA_00071740).

\section{Statistical analysis}

GAP score and LAS were calculated as previously described $[6,19]$. Chi-square test or Fisher's exact test and paired $t$ test were used for group comparisons of categorical and continuous data, respectively. Correlation coefficients were estimated by the Pearson's correlation coefficient formula using GraphPad Prism software (Release 7; GraphPad, La Jolla, CA). Unadjusted logistic regression was used to compare the association between the LAS and GAP with mortality within the first posttransplant year in patients with interstitial lung disease/ idiopathic pulmonary fibrosis. The explanatory power of each prediction model was assessed using likelihood ratio chi-square tests $\left(\mathrm{G}^{2}\right)$ comparing a model with the prediction value, age, gender, and race with a nested model that excluded the prediction value. The nested model was chosen to include available variables potentially associated with mortality following lung transplantation while not overlapping significantly with the variables included in each prediction value. The area under the Receiver Operator Characteristic (ROC) curve was used to estimate the ability of each model to predict mortality within the first year of transplant. A two-tailed $\mathrm{P}$ value of less than 0.05 was used as the cutoff for statistical significance; estimates of uncertainty were presented as 95 percent confidence intervals $(95 \% \mathrm{CI})$. Computations were performed using Stata statistical software (Release 12; StataCorp LP, College Station, TX) and GraphPad Prism software (Release 7; GraphPad, La Jolla, CA).

\section{Results}

Seventy-two subjects were analyzed from our internal database for LT. Fifty-eight subjects received lung transplant and fourteen were removed from the waiting list. Forty-two (72\%) subjects survived past the first posttransplant year. Of the 58 transplanted subjects, six had unavailable data. Fifty-two IPF/ILD subjects were included in the analysis. Thirty-eight survived (73.1\%) and fourteen $(26.9 \%)$ of the 52 died within the first posttransplant year (Figure 1).

The baseline characteristics of the 52 patients listed for lung transplant are shown in table 2. The mean age was 57 years (range: 19-71), 34 (55\%) were male, 53 (85\%) were white, and $24(40 \%)$ had pulmonary hypertension. The mean FVC $\%$ predicted was $46.4 \%$ and mean DLCO was $33.4 \%$ with 19 patients (37\%) being unable to perform DLCO testing; in the 6 excluded subjects, the mean FVC\% predicted was $54.1 \%$ (range $24-80 \%$ ) and DLCO was not done. The 




Figure 1: Enrollment and Outcomes.

mean LAS was 46.8 (range: 31.9-92.1) with 14 (26.9\%) subjects having an LAS $>50$, and the mean GAP score was 4.85 (range: $2-8$ ). Forty-one of the 52 patients had IPF (79\%) with a mean age of 59.1 years, while 11 had another ILD (21\%) with a mean age of 50. The other ILDs consisted of hypersensitivity pneumonitis [3], NSIP [2], respiratory bronchiolitis-ILD/desquamative interstitial pneumonia [1], postbone marrow transplant lung disease [4], and constrictive bronchiolitis/BOOP [1]. The 6 excluded subjects had a mean LAS of 60.9 (range 38.9-89.5). Two survivor subjects and four non-survivor subjects did not undergo pre-transplant right heart catheterization.

\begin{tabular}{|c|c|c|c|c|}
\hline Characteristic & All & $\begin{array}{c}\text { Survivors } \\
\text { (>1 yr) }\end{array}$ & $\begin{array}{l}\text { Non-survi- } \\
\text { vors (died } \\
<1 \mathrm{yr} \text { ) }\end{array}$ & p-value \\
\hline & $N=52$ & $\begin{array}{c}N=38 \\
(73.1 \%)\end{array}$ & $\begin{array}{c}\mathrm{N}=14 \\
(26.9 \%)\end{array}$ & \\
\hline \multicolumn{5}{|l|}{ Age } \\
\hline Age (range) & $57.2(19-71)$ & $57.8(30-71)$ & $55.7(19-69)$ & 0.701 \\
\hline \multicolumn{5}{|l|}{ Sex } \\
\hline Male & $29(55.8 \%)$ & $19(50 \%)$ & $10(71.4 \%)$ & 0.168 \\
\hline \multicolumn{5}{|l|}{ Race } \\
\hline White & $44(85 \%)$ & $32(84 \%)$ & $12(86 \%)$ & 0.897 \\
\hline Black & $5(10 \%)$ & $5(13 \%)$ & $0(0 \%)$ & 0.153 \\
\hline Other & $3(5 \%)$ & $1(3 \%)$ & $2(14 \%)$ & 0.11 \\
\hline GAP index (range) & $4.85(2-8)$ & $4.84(2-7)$ & $4.85(2-8)$ & 0.92 \\
\hline $\begin{array}{l}\text { Lung Allocation } \\
\text { Score (LAS) }\end{array}$ & $\begin{array}{l}46.8(31.9- \\
92.1)\end{array}$ & $\begin{array}{l}45.2(31.9- \\
92.1)\end{array}$ & $\begin{array}{l}51.4(32.5- \\
91.9)\end{array}$ & 0.133 \\
\hline Double LT & $30(58 \%)$ & $21(55 \%)$ & $9(64 \%)$ & 0.559 \\
\hline Diagnosis of IPF & $41(79 \%)$ & $30(78.9 \%)$ & $11(78.5 \%)$ & 0.977 \\
\hline $\begin{array}{l}\text { Time on wait list } \\
\text { (days) }\end{array}$ & $52.6(1-412)$ & $45.9(1-408)$ & $71.0(1-412)$ & 0.329 \\
\hline FVC (L) & $\begin{array}{l}1.71(0.47- \\
3.18)\end{array}$ & $\begin{array}{l}1.70(0.47- \\
3.18)\end{array}$ & $\begin{array}{l}1.71(0.8- \\
2.83)\end{array}$ & 0.964 \\
\hline$\%$ FVC & $\begin{array}{c}46.4 \%(15- \\
85 \%)\end{array}$ & $\begin{array}{c}46.1 \%(16.5- \\
85 \%)\end{array}$ & $\begin{array}{c}47.2 \%(15- \\
75.8 \%)\end{array}$ & 0.823 \\
\hline$\%$ DLCO & $\begin{array}{l}33.4 \% \\
(11.0- \\
61.3 \%)\end{array}$ & $\begin{array}{c}34.6 \%(11.0- \\
59.8 \%)\end{array}$ & $\begin{array}{c}30.4 \%(14.0- \\
61.3 \%)\end{array}$ & 0.426 \\
\hline$\%$ FEV1 & $\begin{array}{c}53.4 \%(34- \\
90.9 \%)\end{array}$ & $\begin{array}{c}52.2 \%(34- \\
90.9 \%)\end{array}$ & $\begin{array}{c}58.2(40- \\
86.3)\end{array}$ & 0.283 \\
\hline BMI & $\begin{array}{c}26.9(14- \\
35.1)\end{array}$ & $\begin{array}{c}27.0(18.6- \\
35.1)\end{array}$ & $\begin{array}{c}26.6(14.0- \\
31.8)\end{array}$ & 0.793 \\
\hline
\end{tabular}

\begin{tabular}{|l|c|c|c|c|}
\hline Characteristic & All & $\begin{array}{c}\text { Survivors } \\
\text { (>1 yr) }\end{array}$ & $\begin{array}{c}\text { Non-survi- } \\
\text { vors (died } \\
<1 \mathrm{yr})\end{array}$ & $\begin{array}{c}\text { p-val- } \\
\text { ue* }\end{array}$ \\
\hline PH & $24(40 \%)$ & $19 / 36(53 \%)$ & $5 / 10(50 \%)^{* *}$ & 0.873 \\
\hline RHC & $46(88.5 \%)$ & $36(94.7 \%)$ & $10(71.4 \%)$ & 0.02 \\
\hline ILD Diagnosis & 41 & 30 & 11 & 0.976 \\
\hline IPF & 3 & 2 & 1 & 0.795 \\
\hline HP & 2 & 1 & 1 & 0.453 \\
\hline NSIP & 1 & 1 & 0 & 0.542 \\
\hline RB-ILD/DIP & 4 & 3 & 1 & 0.928 \\
\hline $\begin{array}{l}\text { Post-BM Trans- } \\
\text { plant }\end{array}$ & 1 & 1 & 0 & 0.542 \\
\hline $\begin{array}{l}\text { Constrictive bron- } \\
\text { chiolitis/BOOP }\end{array}$ & \multicolumn{5}{|l|}{} \\
\hline
\end{tabular}

Table 2: Baseline Characteristics.

\section{Abbreviations}

LT: Lung Transplant

IPF: Idiopathic Pulmonary Fibrosis

FVC: Forced Vital Capacity

DLCO: Diffusion Coefficient of Carbon Monoxide

BMI: Body Mass Index

$\mathrm{PH}$ : Pulmonary Hypertension

RHC: Right Heart Catheterization

ILD: Interstitial Lung Disease

HP: Hypersensitivity Pneumonitis

NSIP: Non-Specific Interstitial Pneumonia

RB-ILD: Respiratory Bronchiolitis Interstitial Lung Disease

DIP: Desquamative Interstitial Pneumonia

BM: Bone Marrow

BOOP: Bronchiolitis Obliterans Organizing Pneumonia

*Unadjusted p-values

**Two of the survivors and 4 non-survivors did not have a right heart catheterization

Data are expressed as number (percent) unless otherwise specified. Data are means with (range)

There was poor correlation between the GAP index and LAS with $r^{2}=0.033$ (Figure 2).

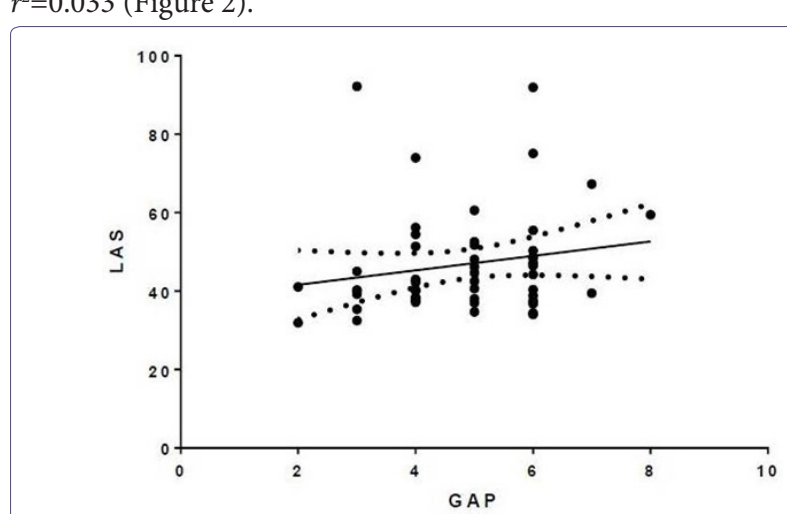

Figure 2: LAS vs. GAP. $\mathrm{r}^{2}=0.033$.

There were 14 deaths $(26.9 \%)$ within the first year post-LT, with $38(73.1 \%)$ of patients surviving $>1$ year post-LT with the median follow-up of 30 months. The GAP index was calculated as near to the listing date as possible, with median time between initial LAS and GAP of 5 weeks (range: 1 day-24 weeks). The difference in time from LAS and GAP is due to time between the most recent pulmonary function testing to the date of listing for lung transplant. Age, race, gender, body mass index, lung function, diagnosis of IPF, double vs. single LT, waitlist time, LAS and GAP index were not significantly different in those who survived or died in the first year (Table 2).

The $\mathrm{G}^{2}$ statistic (likelihood ratio) and $p$-values for the LAS and GAP Index are summarized in table 3: LAS $\mathrm{G}^{2}=1.50(\mathrm{p}=0.22)$, GAP 
$\mathrm{G}^{2}=0.06$ ( $\mathrm{p}=0.81$ ). The ROC curves are presented for each prediction score in figures $3 \mathrm{a}$ and $3 \mathrm{~b}$.

\begin{tabular}{|c|c|c|}
\hline Predictor & LAS & GAP Index \\
\hline \multirow{2}{*}{ G2 } & 1.5 & 0.06 \\
\cline { 2 - 3 } & $\mathrm{P}=0.22$ & $\mathrm{P}=0.81$ \\
\hline
\end{tabular}

Table 3: $\mathrm{G}^{2}$ Statistic Indicating LAS and GAP Contribution to Base nested model of age-gender-race.

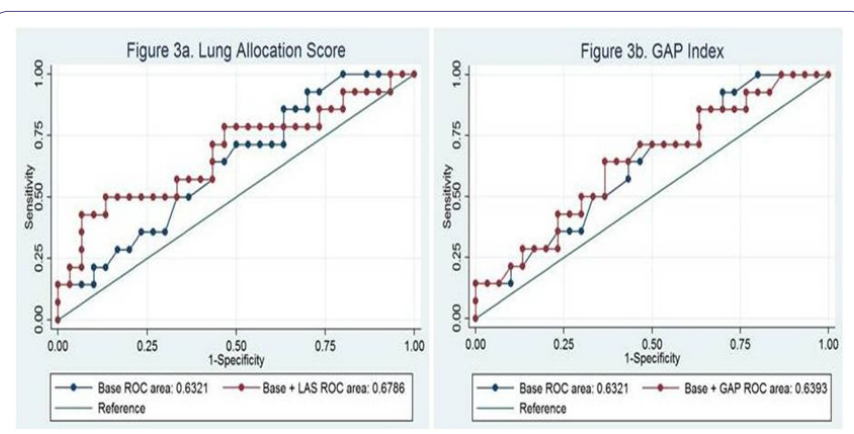

Figure 3: Receiver-Operating-Characteristic (ROC) Curves for Predicting 1-year Mortality Post-transplant. a. Lung Allocation Score (LAS). b. Gender Age Physiology (GAP) Model. Base model includes age, gender and race.

\section{Conclusions}

IPF has a variable course with an overall poor prognosis, and while non-IPFILDs have a better prognosis, both can progress to respiratory failure that may be fatal without lung transplantation. IPF/ILD has risen to the number one indication for LT in the United States since the application of the LAS in 2005 [9]. The GAP model was developed to prognosticate mortality in patients with IPF/ILD. We hypothesized that given the poorer outcome of IPF/ILD post lung transplant, disease specific prognostication methods might prove superior to the LAS at predicting one year post transplant mortality. In this study, we find no correlation between the disease specific model, GAP index, and the LAS once listed for LT. This lack of correlation may be explained by several factors. The GAP index was designed for a different function than the LAS: to predict the natural history of mortality in those with IPF/ILD, in order to aid in decision making for therapy, enrollment in clinical trials, and timing of lung transplant referral or referral to palliative care. The LAS was designed to predict 1-year pre-transplant mortality, but also to take into account posttransplant mortality, so as to prevent transplantation in those patients in whom the procedure is likely to be futile [20]. Some may argue that the LAS does not do the latter very well, as it has been shown in those with the highest LAS, there is increased early posttransplant mortality [21-23], though this did not hold true in our cohort of patients, potentially due to the small subject number. This is the first study to compare these two predictive models in IPF/ILD.

In our cohort of subjects, the LAS and GAP model performed poorly as predictors of early post-transplant mortality. Interestingly, the GAP and LAS also had poor correlation to one another.

There are a number of significant limitations to our study, the greatest being the small sample size. As an exploratory analysis, subjects included are limited to our institution and, therefore, are small compared to the number of lung transplants done yearly. Some components needed to calculate GAP, specifically diffusion capacity are not included in the LAS, thus, it was not possible to derive this data on a national level from the UNOS data base. The small sample size may explain why individual variables which have been shown previously to correlate with mortality were not significant in our study including age, high LAS, presence of pulmonary hypertension, BMI, and FVC. Interestingly, $29 \%$ of non-survivors did not undergo pre-transplant right heart catheterization, whereas only $5 \%$ of survivors did not have this procedure. This may reflect the urgent nature of listing for transplantation in the non-survivors, a clinical scenario which is not always reflected in the calculation of risk prediction models, but which may affect outcomes. Because of the retrospective nature, another limitation in our study is that the GAP index was not calculated at the same time as the LAS when the patient was listed for LT, with a median time of 5 weeks apart. This is due to the timing of their most recent pulmonary function testing from time of listing. This could account for the lack of correlation in GAP and LAS severity if the clinical condition worsened between one score and another, as is not uncommon in end-stage IPF/ILD of the six transplanted patients who were excluded from analysis due to limited data to calculate GAP, 4 lived and 2 died within first posttransplant year which does not significantly alter the mortality outcome ( $26.9 \%$ in our cohort vs. $27.5 \%$ if include 6 missing subject data). The one-year mortality rate seems quite high when compared to all comers for primary lung transplant, but is consistent with IPF-specific outcomes with survival at one year of 73-76\% [7-9]. An additional limitation is the mean $\mathrm{FVC} \%$ predicted and the LAS are higher in the 6 excluded subjects, which shows that the sample could be biased.

Previous publications have shown that predictors of poor outcomes within the first year posttransplant include increased lung allocation score [21], body mass index $>30$ or $<17$ [24-26], increasing age [7], lower lung function [7], lower six minute walk distance [27], and pre transplant mechanical ventilator [28] or extracorporeal support [29]. Our data does not demonstrate a difference in LAS, BMI, age, or lung function between survivors and non-survivors. These risk factors were derived based on all comers to lung transplant. Thus, the lack of correlation in this study may demonstrate the lack of power to show such differences due to the single-center nature of the study. However, it may also suggest some degree of heterogeneity in risk based on the underlying disease diagnosis. Even though we included other ILD diagnoses with IPF in this study, outcomes in end-stage fibrotic lung disease that is not IPF has been demonstrated to be comparable [3-6].

As there are fewer donor organs available than patients in need of lung transplant, continued efforts to best identify those who will most benefit from LT are imperative. The GAP model is a user-friendly tool to help prognosticate those in most need of LT. The LAS will likely evolve over the ensuing years to best deliver donor organs to those in most need, who are also most likely to benefit. This study is the first to compare LAS to a disease-specific model that has been used to prognosticate in patients with ILD/IPF, and emphasizes the need for larger studies focused on posttransplant outcomes in ILD/IPF.

\section{References}

1. King TE Jr, Pardo A, Selman M (2011) Idiopathic pulmonary fibrosis. Lancet 378: 1949-1961.

2. Richeldi L, Collard HR, du Bois RM, Jenkins G, Kolb M, et al. (2013) Mapping the future for pulmonary fibrosis: report from the 17th International Colloquium on Lung and Airway Fibrosis. Eur Respir J 42: 230-238.

3. Hanak V, Golbin JM, Hartman TE, Ryu JH (2008) High-resolution CT findings of parenchymal fibrosis correlate with prognosis in hypersensitivity pneumonitis. Chest 134: 133-138. 
Citation: Silhan LL, Johnson C, Shah PD, Danoff SK (2016) Comparison of the GAP Model and the Lung Allocation Score in Patients with Idiopathic Pulmonary Fibrosis/Interstitial Lung Disease Undergoing Lung Transplantation. J Pulm Med Respir Res 2: 007.

4. Higashiguchi M, Kijima T, Sumikawa H, Honda O, Minami T, et al. (2014) A Retrospective Study of Prognostic Factors in Patients with Interstitial Pneumonia Receiving Long-Term Oxygen Therapy. Lung 192: 729-737.

5. Kelly CA, Saravanan V, Nisar M, Arthanari S, Woodhead FA, et al. (2014) Rheumatoid arthritis-related interstitial lung disease: associations, prognostic factors and physiological and radiological characteristics-a large multicentre UK study. Rheumatology (Oxford) 53: 1676-1682.

6. Ryerson CJ, Vittinghoff E, Ley B, Lee JS, Mooney JJ, et al. (2014) Predicting survival across chronic interstitial lung disease: the ILD-GAP model. Chest 145: 723-728.

7. Yusen RD, Christie JD, Edwards LB, Kucheryavaya AY, Benden C, et al (2013) The Registry of the International Society for Heart and Lung Transplantation: Thirtieth Adult Lung and Heart-Lung Transplant Report--2013; focus theme: age. J Heart Lung Transplant 32: 965-978.

8. Christie JD, Edwards LB, Kucheryavaya AY, Benden C, Dipchand Al, et al. (2012) The Registry of the International Society for Heart and Lung Transplantation: 29th adult lung and heart-lung transplant report-2012. J Heart Lung Transplant 31: 1073-1086.

9. George TJ, Arnaoutakis GJ, Shah AS (2011) Lung transplant in idiopathic pulmonary fibrosis. Arch Surg 146: 1204-1209.

10. Fernandez Perez ER, Daniels CE, Schroeder DR, St Sauver J, Hartman TE, et al. (2010) Incidence, prevalence, and clinical course of idiopathic pulmonary fibrosis: a population-based study. Chest 137: 129-137.

11. Martinez FJ, Safrin S, Weycker D, Starko KM, Bradford WZ, et al. (2005) The clinical course of patients with idiopathic pulmonary fibrosis. Ann Intern Med 142: 963-967.

12. Erbes R, Schaberg T, Loddenkemper R (1997) Lung function tests in patient with idiopathic pulmonary fibrosis. Are they helpful for predicting outcome? Chest 111: 51-57.

13. Lederer DJ, Arcasoy SM, Wilt JS, D'Ovidio F, Sonett JR, et al. (2006) Sixminute-walk distance predicts waiting list survival in idiopathic pulmonary fibrosis. Am J Respir Crit Care Med 174: 659-664.

14. Ley B, Collard HR, King TE Jr (2011) Clinical course and prediction of surviva in idiopathic pulmonary fibrosis. Am J Respir Crit Care Med 183: 431-440.

15. Fell CD, Martinez FJ, Liu LX, Murray S, Han MK, et al. (2010) Clinical predictors of a diagnosis of idiopathic pulmonary fibrosis. Am J Respir Crit Care Med 181: 832-837.

16. King TE Jr, Tooze JA, Schwarz MI, Brown KR, Cherniack RM (2001) Predicting survival in idiopathic pulmonary fibrosis: scoring system and survival model. Am J Respir Crit Care Med 164: 1171-1181.
17. Wells AU, Desai SR, Rubens MB, Goh NS, Cramer D, et al. (2003) Idiopathic pulmonary fibrosis: a composite physiologic index derived from disease extent observed by computed tomography. Am J Respir Crit Care Med 167: 962-969.

18. du Bois RM, Weycker D, Albera C, Bradford WZ, Costabel U, et al. (2011) Ascertainment of individual risk of mortality for patients with idiopathic pulmonary fibrosis. Am J Respir Crit Care Med 184: 459-466.

19. Ley B, Ryerson CJ, Vittinghoff E, Ryu JH, Tomassetti S, et al. (2012) A multidimensional index and staging system for idiopathic pulmonary fibrosis. Ann Intern Med 156: 684-691.

20. Egan TM, Murray S, Bustami RT, Shearon TH, McCullough KP, et al. (2006) Development of the new lung allocation system in the United States. Am J Transplant 6: 1212-1227.

21. Weiss ES, Allen JG, Merlo CA, Conte JV, Shah AS (2009) Lung allocation score predicts survival in lung transplantation patients with pulmonary fibrosis. Ann Thorac Surg 88: 1757-1764.

22. Merlo CA, Weiss ES, Orens JB, Borja MC, Diener-West M, et al. (2009) Impact of U.S. Lung Allocation Score on survival after lung transplantation. J Heart Lung Transplant 28: 769-775.

23. Liu V, Zamora MR, Dhillon GS, Weill D (2010) Increasing lung allocation scores predict worsened survival among lung transplant recipients. Am J Transplant 10: 915-920.

24. Gries CJ, Bhadriraju S, Edelman JD, Goss CH, Raghu G, et al. (2015) Obese patients with idiopathic pulmonary fibrosis have a higher 90-day mortality risk with bilateral lung transplantation. J Heart Lung Transplant 34: 241-246.

25. Culver DA, Mazzone PJ, Khandwala F, Blazey HC, Decamp MM, et al. (2005) Discordant utility of ideal body weight and body mass index as predictors of mortality in lung transplant recipients. J Heart Lung Transplant 24: 137-144.

26. Madill J, Gutierrez C, Grossman J, Allard J, Chan C, et al. (2001) Nutritional assessment of the lung transplant patient: body mass index as a predictor of 90-day mortality following transplantation. J Heart Lung Transplant 20: 288296

27. Martinu T, Babyak MA, O'Connell CF, Carney RM, Trulock EP, et al. (2008) Baseline 6-min walk distance predicts survival in lung transplant candidates. Am J Transplant 8: 1498-1505.

28. Mason DP, Thuita L, Nowicki ER, Murthy SC, Pettersson GB, et al. (2010) Should lung transplantation be performed for patients on mechanical respiratory support? The US experience. J Thorac Cardiovasc Surg 139: 765-773.

29. Bermudez CA, Rocha RV, Zaldonis D, Bhama JK, Crespo MM, et al. (2011) Extracorporeal membrane oxygenation as a bridge to lung transplant: midterm outcomes. Ann Thorac Surg 92: 1226-1232. 